\title{
REFLEXÕES SOBRE A POLÍTICA DE FORMAÇÃO INICIAL A PARTIR DE DADOS DE EGRESSAS DO CURSO DE PEDAGOGIA DA UNICAMP
}

Reflection about initial training policy from data of UNIC AMP pedagogy course

Reflexión acerca de la politica de capacitación inicial de los datos del curso de pedagogía de UNICAMP

Adriana Varani*

Dirce Zan **

\section{Resumo}

Este artigo tem como objetivo apresentar e analisar os dados obtidos a partir de levantamento realizado em 2019 sobre egressas do curso de Pedagogia da Unicamp, na relação com as políticas educacionais atuais. Em especial, o foco está nas orientações para a formação de professores recentemente difundidas em nível tanto nacional quanto estadual de São Paulo e nas egressas do curso de pedagogia da Unicamp. A Deliberação do CEE/SP 154/2017 e a Resolução CNE/CP n0 02/2019, que instituem Diretrizes Curriculares para formação Inicial e Continuada, respectivamente, indicam uma perspectiva de formação respaldada na racionalidade técnica. Esses documentos partem de uma leitura reducionista da influência da formação no desempenho acadêmico dos estudantes da educação básica e, por conseguinte, na qualidade da educação pública.

Palavras-chave: Curso de Pedagogia; Formação inicial de professores; Universidade pública; política de formação de professores. 


\begin{abstract}
This article aims to present and analyze data obtained from a survey conducted in 2019 on graduates of the Pedagogy course at Unicamp, in relation to current educational policies. In particular, the focus was on guidelines for teacher training recently disseminated both at the national and state levels in São Paulo. The Deliberation of CEE / SP 154/2017 and Resolution CNE / CP No. 02/2019, which establish Curricular Guidelines for Initial and Continuing Education, respectively, indicate a perspective of education supported by technical rationality. The reflection of this relationship leads us to question the reductionist reading of the influence of training on the academic performance of basic education students on the quality of public education.
\end{abstract}

Keywords: Pedagogy Course; Initial teacher training; Public university; teacher training policy.

\title{
Resumen
}

Este artículo tiene como objetivo problematizar los datos obtenidos de una encuesta realizada en 2019 a egresados de la carrera de Pedagogía de la Unicamp, en relación con las políticas educativas vigentes. En particular, la atención se centró en las directrices para la formación docente recientemente difundidas tanto a nivel nacional como estatal en São Paulo. La Deliberación de CEE / SP 154/2017 y la Resolución CNE / CP No. 02/2019, que establecen Lineamientos Curriculares para la Educación Inicial y Continuada, respectivamente, señalan una perspectiva de la educación sustentada en la racionalidad técnica. El reflejo de esta relación nos lleva a cuestionar la lectura reduccionista de la influencia de la formación en el desempeño académico de los estudiantes de educación básica en la calidad de la educación pública

Palabras clave: Curso de Pedagogía; Formación docente inicial; universidad pública; política de formación del profesorado.

\section{Introdução}

Este artigo nasceu de uma provocação que nos foi feita durante a apresentação do trabalho intitulado "O curso de Pedagogia e a Deliberação 111/12 do CEE-SP", no Seminário Brasileiro de Educação ${ }^{1}$. Naquele momento, o objetivo era problematizar a

\footnotetext{
${ }^{1}$ Evento organizado pelo CEDEs, ocorrido entre os dias 10 e 12 de dezembro de 2018. Disponível em: "https://www.cedes.unicamp.br/seb/752. O trabalho apresentado deu origem ao artigo "O Curso de
} 
Reflexões sobre a política de formação inicial a partir de dados de egressas do curso de Pedagogia da UNICAMP

interferência do texto legal na organização curricular do curso de Pedagogia da Faculdade de Educação (FE) da Unicamp. Diante do debate apresentado, participantes do evento levantaram questões referentes às egressas ${ }^{2}$ do curso, especialmente acerca de dados que indicassem como tem sido a sua inserção no campo profissional. De certo modo, esse questionamento surgiu a partir da crítica elaborada pelas autoras do trabalho (VARANI; ZAN; GRANDIN, 2019) sobre o ponto de partida da Deliberação em questão. Insistentemente, formuladores de políticas de formação recorrem aos resultados de avaliações educacionais em larga escala, aplicadas a estudantes da Educação Básica, para afirmarem que os cursos de formação de professores do País são inadequados, segundo suas avaliações e critérios peculiares. Pautam-se, na maioria das vezes, nos indicadores de desempenho que estudantes alcançam nessas avaliações e estabelecem uma relação direta entre o baixo desempenho e a formação de professores - em especial, daqueles egressos das universidades públicas.

Em São Paulo, especificamente, membros do Conselho Estadual de Educação (CEE/SP) retomaram o mesmo argumento no momento de homologação da Deliberação analisada por nós, induzindo à crença de que a má qualidade da educação pública do estado era reflexo da atuação de professores e que esses eram formados nas universidades públicas. Partindo desse pressuposto, afirmavam que o grande problema estava no excesso de teoria que fundamentava os cursos, distanciando-se do conhecimento pedagógico e minimizando a importância da prática em seus currículos. Sendo assim, fazia-se necessária a reorientação da formação, partindo dos princípios expressos na Deliberação de 2012, fortemente marcada pela centralidade técnica, pela ênfase no "como ensinar".

Esta insistência em responsabilizar professores ignora outros fatores que interferem na qualidade da educação e vão em direção à culpabilização individual de docentes e estudantes (AFONSO, 2014), além de trabalhar com uma lógica de qualidade que se pauta apenas pelo resultado de desempenho em testes padronizados.

A partir do reconhecimento de que o problema não pode ser interpretado do ponto de vista da responsabilização dos processos formativos, e ao mesmo tempo reconhecendo que tal discurso tem influenciado sobremaneira o imaginário social sobre o trabalho docente dentro das escolas e a formação inicial nas universidades públicas, resolvemos

Pedagogia entre Deliberações”, de autoria de Adriana Varani, Dirce Zan e Luciane Grandin, publicado na revista Educação em 2019.

${ }^{2}$ Optamos pela expressão no feminino, uma vez que há predominância deste gênero no conjunto de dados obtidos para a presente pesquisa. 
discutir o tema partindo do levantamento que realizamos com egressas do curso de Pedagogia da Unicamp.

A provocação feita quando do referido Seminário nos levou a investir esforços na busca por dados que contribuam para compreender as trajetórias dos estudantes formados no curso de Pedagogia da Unicamp. Em parceria com o Centro Acadêmico de Pedagogia (CAP) "Marielle Franco", da FE/Unicamp, realizamos o levantamento de um conjunto de dados sobre egressas do curso. Este artigo, portanto, tem por objetivo apresentar os dados coletados com o intuito de nos ajudar a compreender a trajetória desses exestudantes, na relação com as políticas de formação. Para contextualizar o estudo, apresentaremos uma breve discussão sobre a disputa histórica pelo curso de Pedagogia, que está fundamentada em projetos políticos e educacionais distintos.

\section{As disputas pelo curso de pedagogia}

Não é de hoje que os cursos de formação inicial de professores e, em especial, o curso de Pedagogia, são alvo de questionamento sobre sua qualidade. $\mathrm{O}$ embate entre diferentes posicionamentos está posto historicamente. Entendemos que no campo de formação de professores também se expressam as diferentes lutas sociais. Em especial, destacamos a luta entre, de um lado, os que concebem essa formação como compromisso de Estado e o professor da Educação Básica como um intelectual que atua na produção de cultura e de conhecimento; e, de outro lado, os que a compreendem como parte de uma ação que deve estar aberta à livre concorrência do mercado e pautar-se por um projeto de administração e controle do trabalho do professor. Nessa segunda concepção, por exemplo, ampliam-se os treinamentos, os cursos de "capacitação", a produção de materiais e as orientações que visam, em especial, transformar o trabalho docente na habilidade de uma boa "gestão de sala de aula".

No contexto nacional, recentemente esse embate se amplificou. Em 2015, o Conselho Nacional de Educação publicou as Diretrizes Nacionais para Formação de Professores através da Resolução n. 2. Esse documento resultou de intenso debate com pesquisadores que investigam o campo da formação de professores e as diferentes entidades nacionais que atuam nessa área ${ }^{3}$. Essa resolução aponta para um compromisso público de Estado com a formação de professores, um compromisso com um projeto social justo, pela emancipação de indivíduos e grupos sociais. Sua concepção de formação

\footnotetext{
${ }^{3}$ Parte do histórico desse movimento pode ser conhecido em Dourado e Tuttman (2019); e em Dourado (2015).
} 
Reflexões sobre a política de formação inicial a partir de dados de egressas do curso de Pedagogia da UNICAMP

se pauta pela articulação entre teoria e prática e por uma sólida formação teórica interdisciplinar. Nesse documento, a formação inicial e a formação continuada são entendidas de modo articulado e pautadas pela ideia de que a instituição de Educação Básica é um espaço fundamental para a formação de professores - formulações amplamente defendidas pelos movimentos sociais no campo da formação de professores, como a Associação Nacional pela Formação dos Profissionais da Educação - ANFOPE.

Logo após o golpe parlamentar jurídico-midiático (MORAES, 2018), foram divulgadas novas diretrizes para a formação de professores, que se apresentam em oposição às de 2015 e alinhadas ao novo viés privatista e autoritário que tem assumido as diferentes políticas públicas desde então. Em 2017, um grupo de consultores, vinculado a empresas e assessorias educacionais privadas, foi contratado pelo MEC e elaborou o documento da Base Nacional Comum Curricular posteriormente encaminhado ao CNE. O documento recupera a noção de competência como fonte de orientação da formação de professores e incorpora, a partir de modelo internacional, princípios de um maior controle do trabalho do professor (GONÇALVES; MOTA; ANADON, 2020). O processo que levou à homologação das novas Diretrizes Nacionais para Formação Inicial de Professores pelo CNE em 20 de dezembro de 2019, como relatam Gonçalves, Mota e Anadon (2020), foi atropelado e se deu de forma autoritária, contrariando as manifestações das diferentes entidades educacionais que defendiam a continuidade da reorganização dos currículos dos cursos de licenciatura em diálogo então recentemente desencadeado no interior das universidades públicas com as Diretrizes de 2015.

No entanto, para além do processo, chama a atenção nesse novo documento a separação entre a formação inicial e a continuada de professores, rompendo com uma perspectiva fundamental no texto de 2015, ou seja, a necessária articulação entre os diferentes momentos da formação e a valorização da instituição de Educação Básica como espaço formador. Para além disso, há um silêncio em relação à formação como parte de uma política maior de valorização do profissional do magistério - o que aparece no texto de 2015 - e uma retomada das noções de competência e habilidades como articuladores dos currículos dos cursos de licenciatura. Como expresso no artigo 7, parágrafo II:

reconhecimento de que a formação de professores exige um conjunto de conhecimentos, habilidades, valores e atitudes, que estão inerentemente alicerçados na prática, a qual precisa ir muito além do momento de estágio obrigatório, devendo estar presente, desde o início do curso, tanto nos conteúdos educacionais e pedagógicos quanto nos específicos da área do conhecimento a ser ministrado. (BRASIL, 2019, p. 4) 
Essas competências, sejam específicas e/ou gerais, não fazem menção alguma aos conhecimentos de áreas importantes para o pensamento educacional. Ele está pautado em uma perspectiva pragmática e padronizada de formação e centralizado na prática, como premissa para uma formação de qualidade. Prática aqui concebida como saber fazer, como o domínio do conteúdo a ser ensinado e da melhor técnica para desenvolvê-lo, como um conjunto de competências e habilidades encerradas em si mesmas. Chamam a atenção, conforme destaque de Gonçalves, Mota e Anadon (2020), a noção de conhecimento como neutro e objetivo e a ausência de compreensão da prática como articulada ao conhecimento teórico.

É possível afirmar que o quadro de embate entre políticas que está em jogo atualmente tende a fortalecer posicionamentos em defesa de uma formação inicial que enfatize a necessidade de conhecimento específico e conhecimento pedagógico, de forma dicotômica e restrita, sem considerar outras dimensões formativas.

Entretanto, dois aspectos nos conduzem ao questionamento sobre esta divisão que está posta. O primeiro refere-se à perspectiva de que um processo formativo com estas duas ênfases, sem pensar em estruturas básicas diversas de currículo, pode apenas sobrepô-las no percurso formativo e reproduzir a dicotomia entre os conhecimentos que se expressam nos currículos das Faculdades de Educação e aqueles que se fazem presentes na formação oferecida por faculdades de campos disciplinares específicos. $\mathrm{O}$ segundo aspecto é que esta divisão dos modelos na formação não garante articulação teórico-prática, nem tampouco uma reflexão profunda e crítica sobre realidades e contextos educacionais.

Tais questões também foram identificadas quando na Deliberação do CEE/SP 154/2017. Na próxima seção vamo-nos concentrar no recente movimento desse órgão no que se refere, em especial, ao curso de licenciatura em Pedagogia.

\section{O curso de pedagogia e o CEE/SP}

Ao longo da história do curso de Pedagogia, diferentes proposições sobre a atuação do pedagogo foram se constituindo. Em sua criação no Brasil, há 81 anos, ele nasceu com o propósito de formar o especialista em educação, formar o profissional que iria trabalhar na gestão escolar, na orientação pedagógica, na orientação vocacional, na supervisão, dentre outras denominações de funções de especialistas que existem ou já existiram no País. Desde a década dos anos de 1980, os movimentos sociais voltados à 
Reflexões sobre a política de formação inicial a partir de dados de egressas do curso de Pedagogia da UNICAMP

formação dos profissionais da educação organizaram-se e, com base numa leitura da realidade da situação educacional brasileira, passaram a defender uma formação inicial de professores em nível superior. Esse movimento expressou com força sua posição e garantiu, no artigo 62 da Lei de Diretrizes de Bases (LDB/96), que a formação do professor para a Educação Infantil e Séries Iniciais do Ensino Fundamental deveria ocorrer no ensino superior, no curso de Pedagogia. Desde então, em um movimento de muita mobilização, negociação, embates de diferentes grupos, foram estabelecidas as Diretrizes Curriculares Nacionais para o curso de Pedagogia (2006), tornando a formação para os professores desses níveis educacionais o foco central da organização curricular do curso.

Esse debate está também centrado na definição do caráter dessa formação. Com a defesa de uma base comum nacional pela formação dos professores, a ANFOPE defende que o curso de Pedagogia se balize por princípios historicamente defendidos por entidades educacionais e se contrapõe à ideia de um conjunto de conteúdos mínimos a serem trabalhados na formação inicial (FREITAS, 2019). Estes princípios estão na direção da tomada da docência como base.

O educador [...] é aquele que: tem a docência como base da sua identidade profissional; domina o conhecimento específico de sua área, articulado ao conhecimento pedagógico, numa perspectiva de totalidade do conhecimento socialmente produzido, que lhe permite perceber as relações existentes entre as atividades educacionais e a totalidade das relações sociais em que o processo educacional ocorre; é capaz de atuar como agente de transformação da realidade na qual se insere. (ANFOPE, 1989, p.11)

Nesta perspectiva, a formação de professores dos anos iniciais ocorre no curso de Pedagogia, e a ação docente não se restringe ao trabalho em sala de aula. Entende-se que o exercício do magistério é a base sobre a qual outras formas de atuação do pedagogo se constituirão. Parte-se da noção de que, para atuar na gestão educacional, em suas diferentes dimensões, é fundamental a experiência de magistério do profissional. Ser professor é o que confere a identidade necessária para um gestor na educação.

Em outra perspectiva, Libâneo (2001, p. 6) traz uma compreensão de diferentes identidades no curso de Pedagogia. Partindo do pressuposto de que a Pedagogia é o "campo do conhecimento que se ocupa do estudo sistemático da educação - do ato educativo, da prática educativa como componente integrante da atividade humana", o autor desenvolve a ideia de que existe o pedagogo lato sensu, referindo-se aos professores, e o pedagogo stricto senso, que remete aos pesquisadores da educação. Para ele o curso de Pedagogia forma o pedagogo especialista, ou seja, o pedagogo stricto 
senso. Nesta perspectiva há uma alusão à divisão da formação entre o bacharel e o licenciado em Pedagogia.

Atualmente, os diferentes Conselhos Estaduais e o Conselho Nacional de Educação têm também indicado mudanças que almejam para o curso de Pedagogia. No momento da escrita deste artigo, o CNE pauta em suas reuniões a "Revisão das Diretrizes Curriculares Nacionais para o Curso de Pedagogia" de 2006, conforme consta em agenda do CNE, da data de 9 de novembro de $2020^{4}$, sem realização de consulta pública. Vale também lembrar que em nível federal houve o Parecer CNE/CP n ${ }^{0} 14 / 2020$, pela Portaria MEC n 882, de 23/10/2020, e a publicação da Resolução CNE/CP n 1, de 27/10/2020, que institui as Diretrizes Curriculares Nacionais para a Formação Continuada de Professores da Educação Básica e a Base Nacional Comum para a Formação Continuada de Professores da Educação Básica (BNC-Formação Continuada).

No estado de São Paulo, partindo das críticas pouco fundamentadas sobre a baixa qualidade dos cursos nas universidades públicas, como argumentamos anteriormente, o CEE/SP homologou em 2011 uma primeira versão das Diretrizes para os Cursos de Formação de Professores, que culminaram com a aprovação da Deliberação CEE/SP 154/2017, “que Fixa Diretrizes Curriculares Complementares para a Formação de Docentes para a Educação Básica nos Cursos de Graduação de Pedagogia, Normal Superior e Licenciaturas, oferecidos pelos estabelecimentos de ensino superior vinculados ao sistema estadual”. As ações do CEE/SP durante o processo de elaboração e implementação da referida Deliberação repercutiram e foram disseminadas também pela grande imprensa do País. O tom era o impositivo, ferindo a autonomia universitária (VARANI; ZAN; GRANDIN, 2019), como que desejosos de submissão dessas instituições a uma lógica de setores representados pelo CEE - em especial, os empresários educacionais. Como exemplo disso, podemos citar a reportagem da Folha de S. Paulo de 24 de maio de 2014 (grifo nosso): "Conselho impõe mais aula prática na pedagogia de USP, Unesp e Unicamp”. A reportagem assim inicia seu discurso:

O Conselho Estadual de Educação decidiu obrigar USP, Unesp e Unicamp a mudarem seus currículos dos cursos de pedagogia e licenciatura, que formam professores para o ensino básico. A produção semântica não deixa dúvidas de que ao Conselho Estadual de Educação interessa determinar, impor, obrigar. Estes são verbos que não cabem à conquista da autonomia universitária no artigo 207 da Constituição Federal de 1988. (p. 11, grifo nosso)

\footnotetext{
${ }^{4}$ Disponível em: https://formacaoprofessor.com/2020/11/12/cne-revisa-dcns-da-pedagogia-sem-ouvir-asfaculdades-de-educacao-e-entidades-da-area. (Acesso em 7 de nov de 2020)
} 
Reflexões sobre a política de formação inicial a partir de dados de egressas do curso de Pedagogia da UNICAMP

O seu teor aponta para uma formação de professores pautada pelo ensino mais técnico, em que o trabalho com fundamentos da educação fica secundarizado, e a ênfase ao debate sobre "como se ensinar" é ampliada, conforme já desenvolvido por Varani, Zan e Grandin (2020). Neste cenário aparece a defesa da formação de professores em nível médio, apesar de parecer que o debate havia avançado e superado a questão sobre em qual nível de ensino - cursos médios ou superior - o professor deveria ser formado. No entanto, a partir desses movimentos recentes no estado de São Paulo, salta aos olhos o perigoso retrocesso que estamos vivendo, em especial com a proposta de um itinerário formativo no ensino médio para formação do Técnico em Educação (FREITAS, 2020) ${ }^{5}$.

Em meio a esse turbilhão de mudanças e disputas é que se encontra o curso de Pedagogia da Faculdade de Educação da Unicamp, a partir do qual construímos nossa amostragem de egressos.

\section{O curso de pedagogia da UNICAMP}

O curso de Pedagogia teve início na Unicamp em 1974, com o objetivo de formar especialistas para a educação, como era a ênfase dada a esse curso no território nacional naquele momento ${ }^{6}$. Quando de sua criação eram oferecidas 3 habilitações: orientação educacional, supervisão escolar e administração escolar. A habilitação para atuar no magistério das séries iniciais só foi incorporada ao curso após 1977. Ao longo de seus mais de 45 anos o curso passou por diferentes reformas, em consonância com o movimento nacional em que as diferentes entidades educacionais estiveram envolvidas, contribuindo para uma aproximação de sua finalidade e estrutura curricular aos projetos e perspectivas defendidas por tais movimentos.

Dentre as principais mudanças destacamos a criação do curso noturno em 1991, que significou um importante movimento para a democratização do acesso ao curso; a reforma curricular de 1997, quando o curso rompeu com as habilitações, mesmo em um período em que elas ainda se faziam presentes nos cursos de Pedagogia pelo país; e a adequação a partir das Diretrizes Curriculares de 2006, que impactou, em especial, a organização e a carga horária dos estágios (JEFFREY; ASSIS; GRANDIN, 2016).

\footnotetext{
5 Disponível em: https://www1.folha.uol.com.br/educacao/2020/08/sao-paulo-recria-magisterio-paraformar-assistente-de-professor.shtml

${ }^{6}$ As informações aqui apresentadas foram retiradas do Projeto Político-Pedagógico do curso de Pedagogia da Faculdade de Educação/Unicamp, disponível em: https://www.fe.unicamp.br/pffe/pagina basica/1200/projeto_pedagogico_pedagogia _ catalogo_20190.pdf (Acesso em: 07 dez. 2020)
} 
Em uma análise do Projeto Político-Pedagógico (PPP) do curso de Pedagogia da Unicamp, é possível observar a consonância com a tendência mais recente que se apresenta para a formação do pedagogo, ou seja, a formação do professor para as séries iniciais e do gestor. Numa perspectiva de superação das antigas habilitações do curso, propõe-se uma formação que tenha como fundamento a abrangência do campo educacional. A partir de uma análise mais aprofundada, é possível observarmos que o currículo, na forma como se apresenta, orienta para a possibilidade de formação de perfis profissionais diferentes: professor de Educação Infantil, professor dos anos iniciais do Ensino Fundamental, atuação na Educação Não Formal e na Gestão Pedagógica e Educacional.

O currículo permite um certo trânsito dos estudantes entre as diferentes áreas e perspectivas formativas, contribuindo para uma formação mais flexível e diversificada.

Importante ressaltar que todas as alterações ao longo de todos esses anos foram pautadas por muitos debates e amadurecidas em seminários internos, com envolvimento de docentes e estudantes. Grupos de Trabalho foram criados nos últimos dez anos, tendo como pauta a busca por melhor articulação, no que se refere à presença dos conhecimentos propiciados por docentes da FE na formação dos professores na Unicamp, em seus diferentes cursos de licenciatura, nos quais se inclui o de Pedagogia. Os movimentos de reflexão e alteração sempre culminaram na análise e na aprovação nas diferentes instâncias da FE/Unicamp. A avaliação do currículo dos cursos de formação de professores está sempre em pauta nas várias câmaras da Faculdade e da Universidade ${ }^{7}$. Após este processo interno de ampla discussão e consequente aprovação, o CEE/SP realizava a revalidação dos cursos, conforme o estabelecido na legislação nacional.

No entanto, desde a promulgação das Deliberações do CEE/SP, a partir de 2012, o curso tem vivido sob a forte pressão para adequações a partir do referencial de formação que sustenta tais documentos e sobre o qual já debatemos anteriormente.

Foi nesse contexto que em 2014 o curso promoveu novas adequações, na sua maioria, buscando explicitar algumas das exigências do CEE/SP, que já se faziam presentes na organização curricular do curso, e reafirmando os princípios e as perspectivas curriculares que são fundantes na formação do pedagogo pela Unicamp. Através também de diferentes movimentos, a FE segue lutando por manter a concepção

\footnotetext{
${ }^{7}$ Uma dessas instâncias é a Comissão Permanente de Formação de Professores da Unicamp, criada em 2003, no âmbito do processo de reorganização da oferta dos cursos de licenciatura na universidade. Essa comissão, presidida por docente da Faculdade de Educação, escolhido entre seus pares (ZAN, 2019), é um órgão vinculado à Pró-Reitoria de Graduação e é constituída pelo conjunto de coordenadores dos cursos de licenciatura da Universidade.
} 
Reflexões sobre a política de formação inicial a partir de dados de egressas do curso de Pedagogia da UNICAMP

de professor na qual acredita e que tem fundamentado sua história: um profissional com formação intelectual e autônoma, com postura ética e compromisso social com a escola pública e que tem na prática educativa, articulada à pesquisa, o foco de todo o curso.

Nesse sentido, desde 2019 foi reafirmada a possibilidade de integralização do curso diurno em oito semestres, e o curso noturno no período de dez semestres. O estudante, para cursar o estágio curricular, necessita ter cumprido pelo menos $30 \%$ das disciplinas do curso. Importante destacar que os estágios têm início somente após o $5 .^{\circ}$ semestre do curso e têm como objetivo proporcionar a "imersão e vivência em distintos campos de estágio, na dimensão da docência e da gestão democrática, tanto em espaços formais quanto não-formais" ". Além do estágio curricular supervisionado, a prática como componente curricular definida como atividade de formação extracurricular, com carga didática de 450 horas a ser realizada ao longo do curso, entre um conjunto de disciplinas, é compreendida como um dos eixos integradores do curso de Pedagogia-Unicamp.

Em síntese, podemos dizer que o estágio curricular supervisionado e a prática curricular constituem um núcleo de formação que tem o intuito de estabelecer uma relação teórico-prática com ênfase no magistério da educação infantil, nos anos iniciais do ensino fundamental, bem como na gestão educacional, ao longo de todo curso, de forma integrada aos demais. O curso está organizado em núcleos de formação que se propõem integrados: disciplinas teórico-práticas; estágio curricular supervisionado; disciplinas eletivas; prática curricular; integração curricular; e trabalho de conclusão de curso.

O curso tem como princípios fundantes a valorização do trabalho pedagógico como base da formação do profissional da educação; a formação teórica sólida, interdisciplinar e articulada; a pesquisa como eixo de formação; a prática e os estágios como eixo articulador da formação; o trabalho coletivo com envolvimento e interação entre diferentes departamentos da faculdade e docentes do curso, em especial, através das disciplinas de Pesquisa e Prática Pedagógica, dos Seminários de Integração Curricular e dos Estágios; a possibilidade de ampliação e aprofundamento de conhecimentos, em especial, a partir do conjunto de disciplinas eletivas; e a abertura para que estudantes cursem disciplinas em outros Institutos e Faculdades da Unicamp, além do reconhecimento de experiências não disciplinares como elementos curriculares relevantes para a formação do pedagogo, por meio das práticas curriculares.

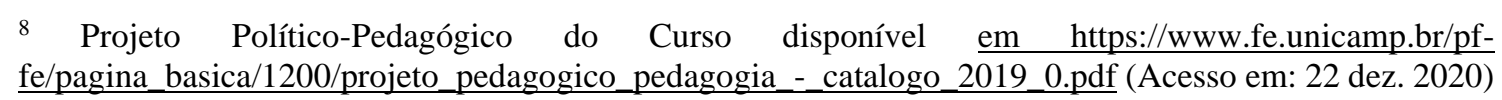


Entretanto, uma das grandes dificuldades que temos é em acompanhar e conhecer a trajetória dos ex-estudantes do curso de pedagogia da Unicamp. Os estudos sobre trajetórias de egressos, embora já consolidados em diferentes países pelo mundo, ainda se colocam como um grande desafio para pesquisadores brasileiros, em especial, no que se refere aos profissionais formados pelas universidades públicas (PAUL, 2015). Nesse sentido é que realizamos um levantamento, ainda inicial, sobre a trajetória de egressas do curso de Pedagogia da FE/Unicamp, na expectativa de que uma pesquisa sobre egressos, assumida como política institucional, possa se desenvolver em futuro próximo.

\section{As egressas da FE/UNICAMP: Uma aproximação}

No ano de 2019 foi instituído um grupo de trabalho no interior da FE para atuar na reformulação do curso de Pedagogia. Este grupo de trabalho reunia representantes docentes, discentes e a coordenação do curso. Em setembro de 2019, no âmbito desse processo, surgiu a necessidade de apresentar um quadro sobre as egressas do curso. Tal tarefa coube aos representantes discentes, juntamente com a representante docente ${ }^{9}$, que se organizaram e produziram um questionário que foi respondido pelas egressas através da plataforma Googleforms. O formulário foi encaminhado em nome do CA "Marielle Franco", a partir de vínculo mantido entre representantes discentes e ex-estudantes.

Uma das maiores dificuldades de iniciativas como essa é a comunicação com os egressos, uma vez que, na sua maioria, os contatos que a instituição tem arquivados, desde o período em que eram estudantes, se encontram desatualizados ou por alguma razão não se obtém retorno do contato realizado. Dessa vez, investimos na divulgação da iniciativa através das redes sociais, na tentativa de alcançar um universo maior de egressas. Foram utilizadas as páginas de ex-alunos da Faculdade de Educação e dos atuais estudantes, que se encontram ativas no Facebook, além dos 320 e-mails que estavam registrados na coordenação do curso de Pedagogia e que contemplavam alunas egressas durante os anos de 2014 e $2018^{10}$. O questionário aplicado às egressas reunia um conjunto de questões que orbitavam sobre os seguintes assuntos: ano de ingresso ${ }^{11}$ e de saída do curso de

\footnotetext{
${ }^{9}$ Aqui nos referimos às representantes discentes - Rebeca de Souza Assis e Thaís Lemi Souza - e à representante docente, Adriana Varani.

${ }^{10}$ Para o envio por email, contamos com a colaboração da estudante Hosana Almeida da Silva, bolsista do Programa de Assistência Social (BAS) da Universidade Estadual de Campinas, a quem agradecemos pelo trabalho realizado.

${ }^{11}$ Importante ressaltar as formas de ingresso que estão vigentes na universidade: vestibular, remanejamento interno de curso, exame para estudantes de outros cursos de pedagogia que concorrem a vagas ociosas no curso (transferência) e o *Programa de Formação Interdisciplinar Superior (PROFIS), um programa da Unicamp que seleciona estudantes da rede pública da cidade de Campinas que obtiveram melhor
} 
Pedagogia da FE/UNICAMP; forma de ingresso no curso; dados sobre a condição de trabalho; vínculo trabalhista estabelecido (celetista, concursado, autônomo); rede de ensino a que está vinculado (Pública - Rede Municipal, Pública - Rede Estadual, Rede Privada, Público - Rede Federal, outra, Não trabalha na área educacional); área de atuação; e ao final houve uma questão aberta para explicitarem seus sentimentos em relação ao curso de Pedagogia da Unicamp e sua repercussão na vida profissional e pessoal.

Iniciamos a apresentação dos dados, caracterizando os respondentes no que se refere ao ano de ingresso na universidade. Há uma predominância de ingressantes entre os anos de 2010 e 2014. Esta predominância se deu em razão da atualização dos dados das egressas pela coordenação de curso de Pedagogia e por comporem a lista de e-mails para os quais enviamos mensagem, solicitando o preenchimento do formulário. Vale ressaltar que, por termos divulgado o formulário inclusive nas redes sociais, egressas de turmas anteriores também responderam ao questionário, como consta no gráfico abaixo. Esta informação é relevante para compreendermos que as respostas obtidas representam a visão de estudantes que passaram pela $\mathrm{FE}$ em diferentes momentos históricos da instituição e, portanto, também viveram diferentes propostas curriculares, entretanto com maior incidência entre 2010 e 2014.

\section{Gráfico 1 - Ano de ingresso no curso}

desempenho no ENEM para ingressarem na universidade sem passar pelo exame do vestibular. Após dois anos de uma formação interdisciplinar, esses estudantes escolhem o curso de graduação que almejam concluir, a partir de um total de vagas reservadas para os que ingressaram pelo programa.* 


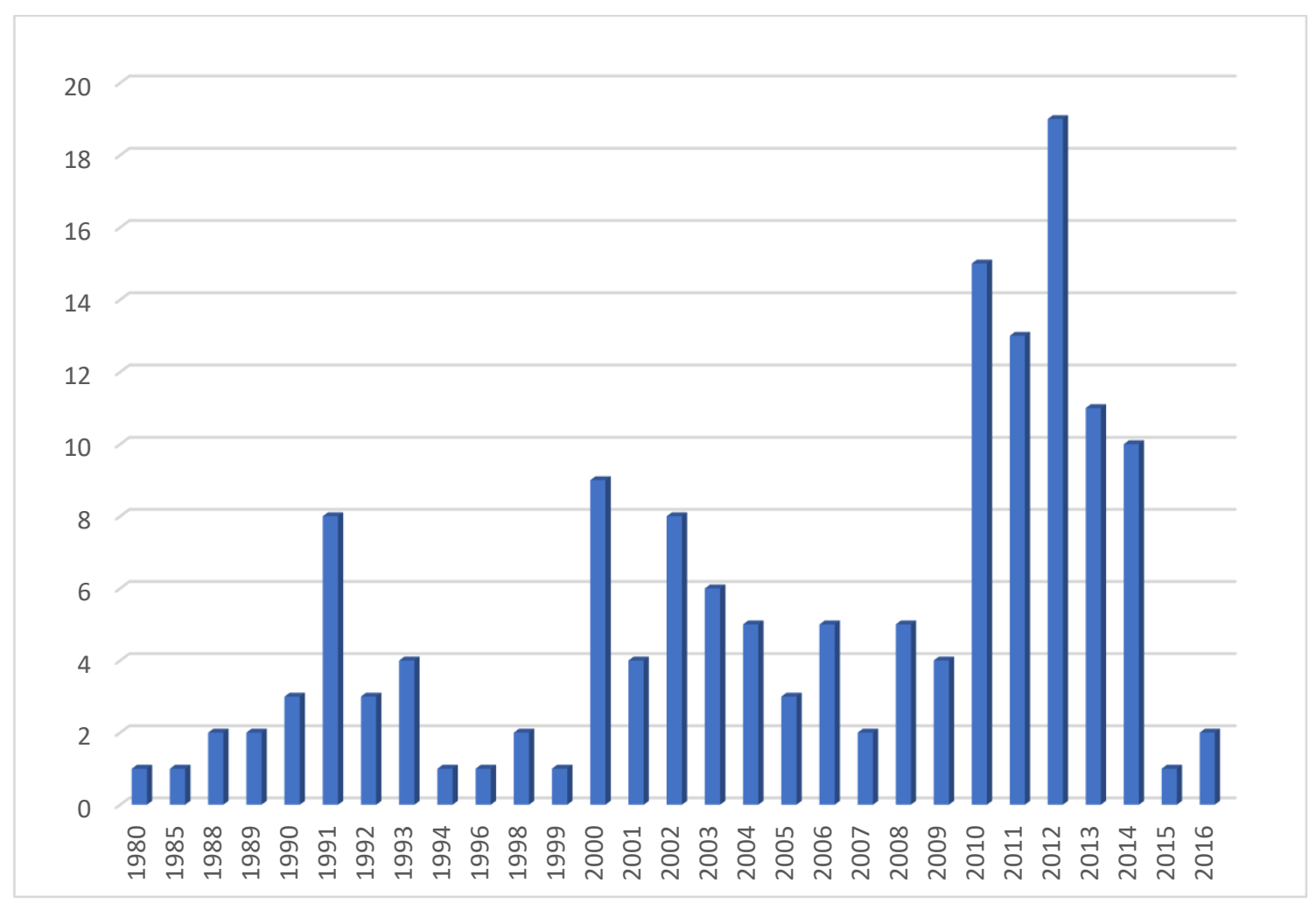

Fonte: elaborado pelas autoras

O intervalo de finalização do curso também se concentra nos cinco anos seguintes ao ingresso da maioria dos respondentes, ou seja, entre os anos de 2014 e 2018, conforme o Gráfico 2. Em sua história o curso de Pedagogia da FE/UNICAMP sempre ofertou um curso com variação de quatro a cinco anos de duração. A matriz curricular das turmas ofertadas em período integral contempla um período de quatro anos para integralização e cinco anos para as turmas do noturno.

\section{Gráfico 2 - Ano de finalização do curso}


Reflexões sobre a política de formação inicial a partir de dados de egressas do curso de Pedagogia da UNICAMP

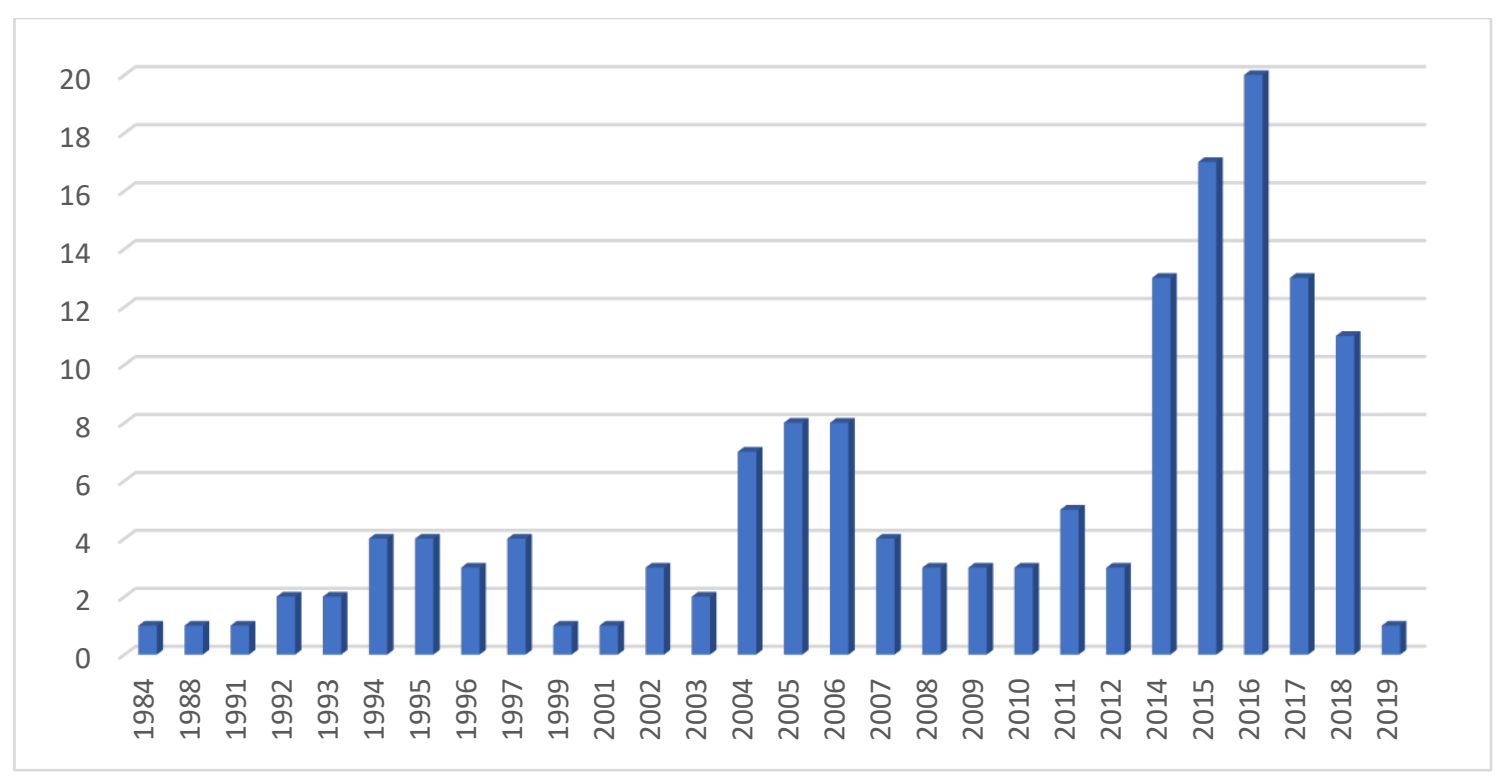

Fonte: elaborado pelas autoras

A partir das respostas obtidas, é possível afirmarmos que praticamente a totalidade das egressas estava trabalhando na ocasião do questionário (ver Gráfico 3).

\section{Gráfico 3 - Egressas que trabalham}

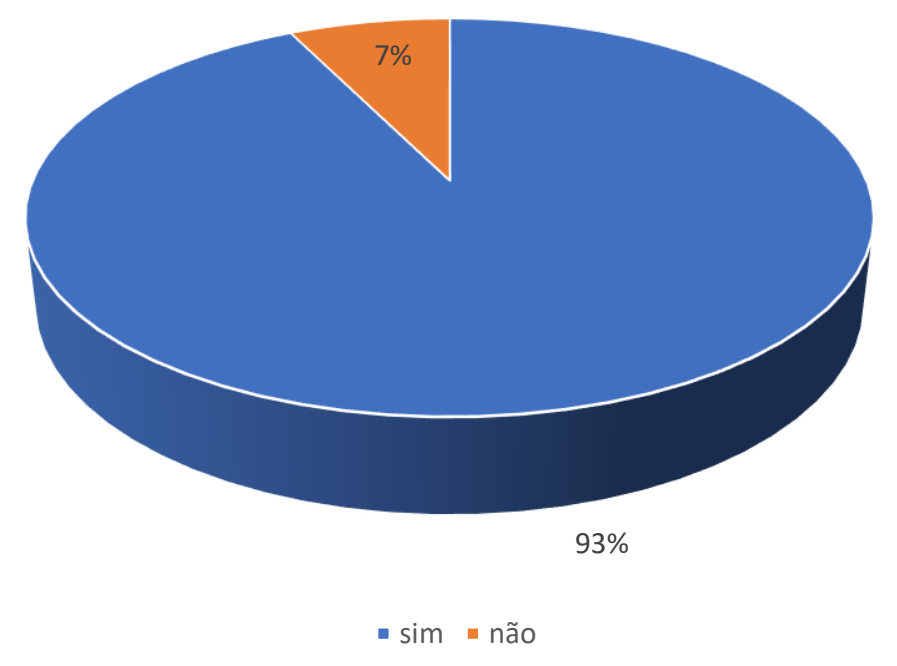

Fonte: elaborado pelas autoras 
Para fins de compreensão do local e do tipo de vínculo na atuação do grupo que trabalha, os bolsistas de pós-graduação foram computados na categoria de não trabalhadores (Gráfico 4). O instrumento não especificou se os bolsistas estão afastados de suas atividades docentes enquanto desenvolvem suas pesquisas e estudos nos cursos de mestrado e doutorado, o que é recorrente no PPGE da FE/UNICAMP.

\section{Gráfico 4 - Tipo de vínculo trabalhista}

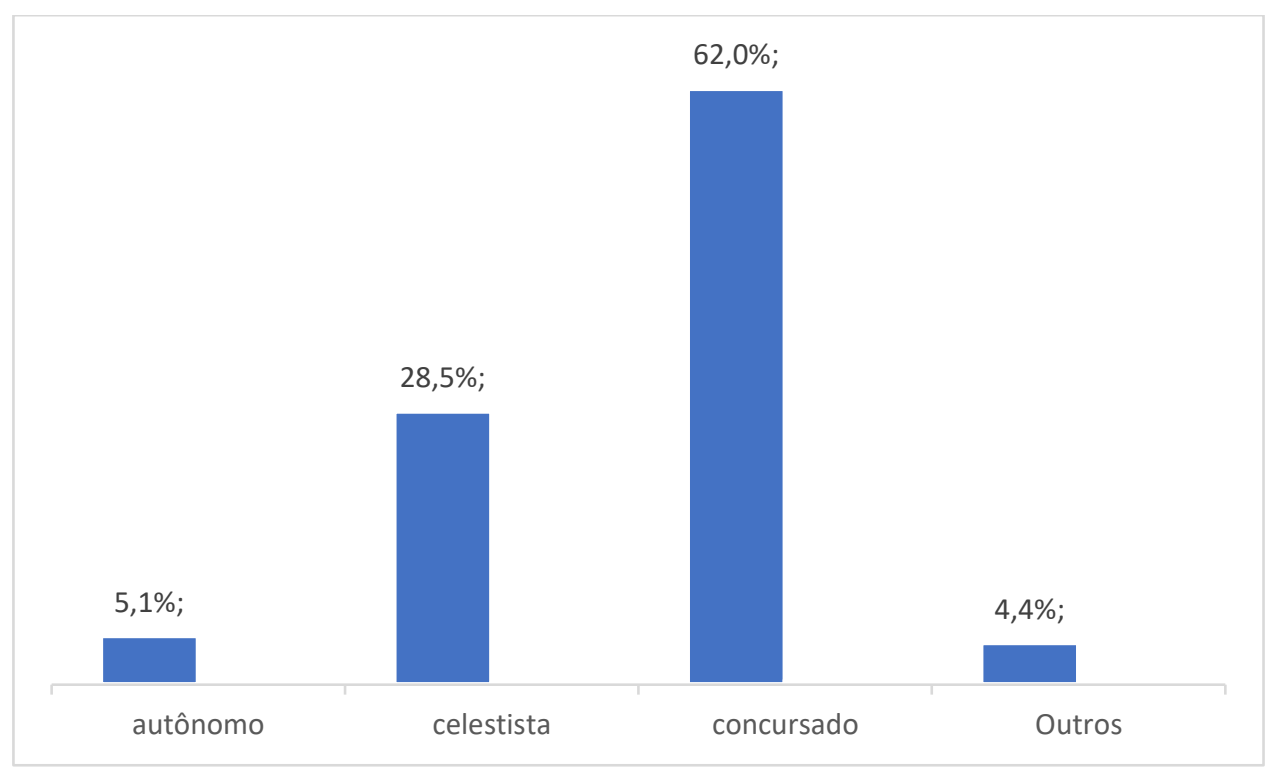

Fonte: elaborado pelas autoras

Dos respondentes que declararam exercer alguma atividade remunerada, $62 \%$ são concursados e $29 \%$ são celetistas, ou seja, contratados com registro em carteira de trabalho, o que, de certo modo, reflete o processo de mudança na forma de contratação de professores que está em curso no Brasil desde os anos de 2010. Dados analisados por Souza (2013) apontam para um aumento na contratação de docentes pelo setor público, que tem abdicado da forma tradicional do concurso público e da estabilidade do profissional. Esses dados revelam o crescimento de vínculos contratuais com base no Código da Legislação Trabalhista (CLT). Isso impacta diretamente o salário e as condições de trabalho dos professores, pois, conforme indica o autor, os professores concursados são os que recebem melhores salários. 
Interessante observar que nesse grupo surge um percentual, ainda pequeno (5\%), de profissionais que atuam de forma autônoma. Talvez esse seja um indicativo de que há, no grupo estudado, a ampliação de vínculos como microempresários.

\section{Gráfico 5 - Local de atuação}
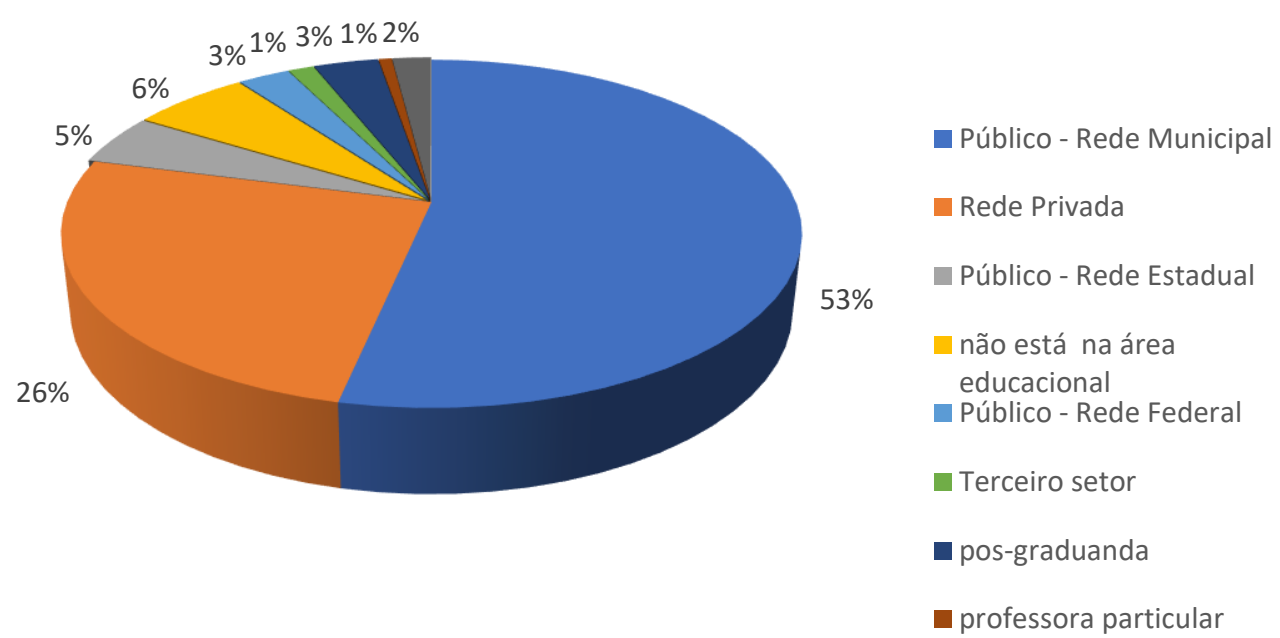

Fonte: elaborado pelas autoras

O Gráfico 5 demonstra em que instituição as egressas do curso de Pedagogia atuam: $61 \%$ atuam no ensino público, distribuídos entre as redes municipal, estadual e federal, enquanto $26 \%$ atuam na rede particular de ensino.

Voltamos à questão mobilizadora da escrita deste artigo, referente à responsabilização da formação de professores realizada nas universidades públicas paulista pelo precário desempenho dos estudantes da Educação Básica em avaliações externas ou pela baixa qualidade da educação pública. Para tanto, tomemos os dados que indicam, no Gráfico 6, o nível de atuação das egressas do curso de Pedagogia da UNICAMP. 


\section{Gráfico 6 - Nível de ensino em que atuam as egressas}

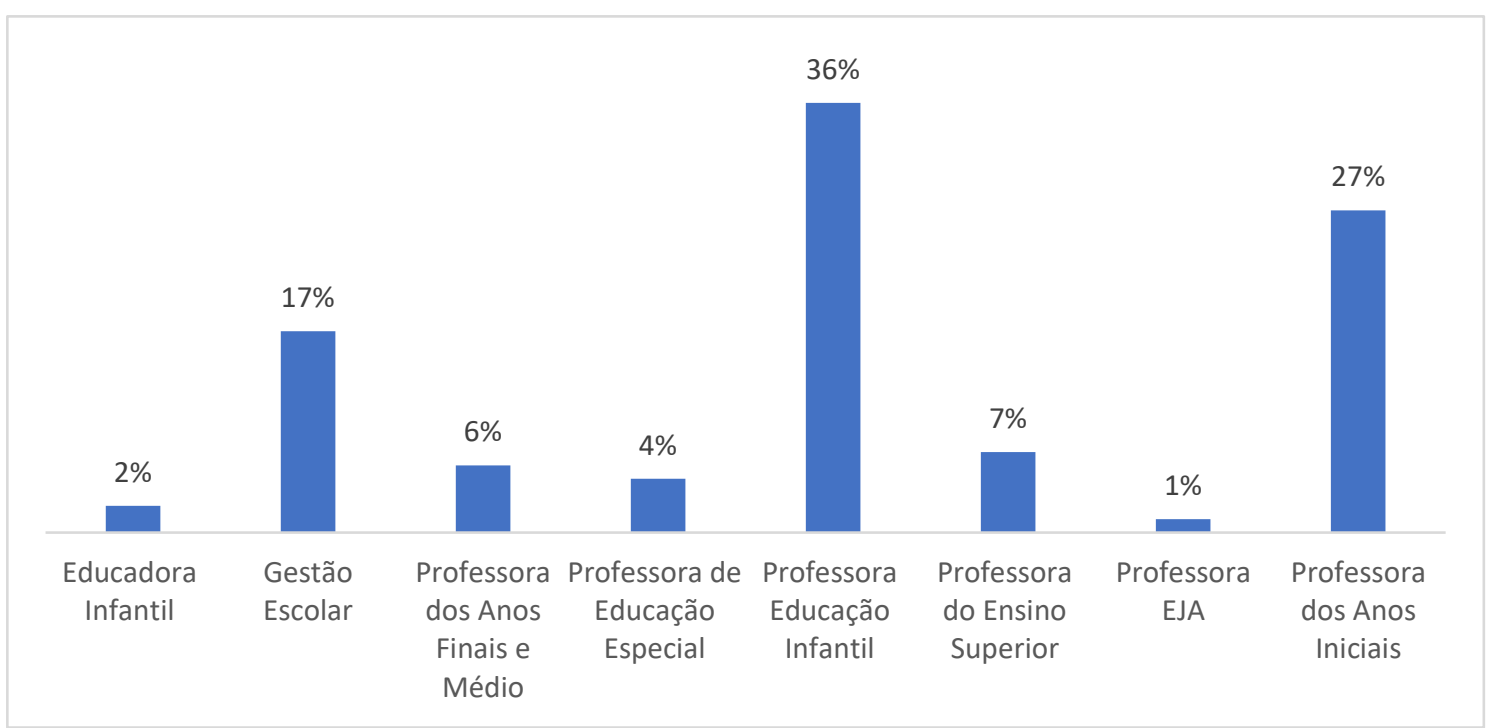

Fonte: elaborado pelas autoras

Conforme informação anterior, do total de respondentes, $61 \%$ atuam na rede pública de ensino.

No levantamento indicativo do nível em que atuam na rede pública, percebemos um grande número de profissionais que saem do curso de Pedagogia e são contratados como professores na educação infantil, totalizando um percentual de $36 \%$ dentre aqueles que estão na rede pública. Há também um grupo que atua como educador infantil, e não como professor de educação infantil. Se somarmos o percentual de professores de educação infantil ao percentual de educadores infantis, chegamos a 38\% das egressas.

O nível de ensino recorrentemente avaliado pelos exames nacionais e internacionais e no qual os pedagogos atuam são os anos iniciais do Ensino Fundamental. A porcentagem de egressas que atuam diretamente com esse nível de ensino específico para o qual o curso de Pedagogia forma e que passam por avaliação externa de desempenho é de $27 \%$.

Há um grupo respondente que atua nos anos finais do Ensino Fundamental e no Ensino Médio, o que correspondente a $6 \%$. Estes níveis também passam por avaliações de desempenho. Neste caso, os respondentes que atuam nestes níveis, provavelmente, possuem formação em uma segunda licenciatura, uma vez que, para atuar nesses níveis, exige-se formação específica nas diferentes disciplinas. Podemos afirmar que, em média, 
Reflexões sobre a política de formação inicial a partir de dados de egressas do curso de Pedagogia da UNICAMP

o número de professores egressos da Pedagogia que atuam como professores na educação pública nos níveis alvos de avaliação externa, é de $33 \%$.

Esta amostra de dados pode nos levar a refletir sobre a lógica hegemônica da relação direta entre a formação de professores em universidades públicas e o desempenho escolar que legisladores tentam estabelecer. Neste caso, esta reflexão ficará circunscrita à realidade da Unicamp.

Tomemos outros dados quantitativos que agregam a esta informação do percentual de professores que atuam em redes públicas de ensino. O curso de Pedagogia da Unicamp forma, em média, 60 professores anualmente ${ }^{12}$. Desta média, aproximadamente $33 \%$ se dirige para o nível de ensino da rede pública, que passa por avaliação externa, a saber, Ensinos Fundamental e Médio, conforme os dados obtidos. Para cotejar esta análise, é necessário trazer dados de contexto da região em que a UNICAMP está inserida. Importante enfatizar que a Unicamp se localiza numa região metropolitana (RMC) que envolve 20 unidades administrativas e é a única universidade pública que tem o curso de Pedagogia. Na RMC havia 10.913 professores dos anos iniciais, segundo Censo da Educação Básica 2019, do INEP ${ }^{13}$. A cidade de Campinas, em 2019, tinha 3763 professores atuando nos anos iniciais do Ensino Fundamental.

Infelizmente não obtivemos a demanda anual por novos professores na RMC, que poderia reforçar nossa leitura contextual. Entretanto, os números apresentados indiciam que o número de egressas do curso de Pedagogia da Unicamp não é suficiente para atender a Região, no nível de atuação dos anos iniciais do Ensino Fundamental. Decorrente desta leitura, a culpabilização da ação da universidade pelo mau desempenho dos estudantes em avaliação externa nos parece bastante frágil.

Para além da justificativa quantitativa acima explicitada, há a necessidade de se contrapor a esta lógica hegemônica, que insiste em tentar explicar o problema da construção da qualidade educacional por apenas uma perspectiva analítica, ou seja, a má formação dos professores da Educação Básica. Sobre a relação direta que reiteradamente se veicula nos discursos e nas práticas políticas, concordamos com os argumentos de Sordi e Freitas (2013, p. 92), para quem há dois movimentos de políticas educacionais na construção da qualidade: o primeiro "escolhe o professor como ator principal para em seguida responsabilizá-lo, exclusivamente, pelos resultados da escola"; o segundo propõe confiança irrestrita no professor, através de diferentes ações, como pela elevação de sua

\footnotetext{
${ }^{12}$ Informação obtida na Secretaria da Coordenação de Curso de Pedagogia da FE/UNICAMP

${ }^{13}$ https://inepdata.inep.gov.br/analytics/saw.dll?Dashboard
} 
qualificação, salários adequados, condições de trabalho, número de alunos reduzido em sala de aula. O segundo movimento ainda padece de centrar os olhos nos outros atores sociais que influenciam na construção de determinada qualidade. Dentre estes outros atores, não podemos deixar de enfatizar que estão inclusas as condições construídas externamente à escola, como as desigualdades econômicas e sociais. Desta forma, não é possível acreditar que basta uma determinada formação de professores para que superemos os índices negativos no desempenho escolar.

Afonso (2014) denomina essa lógica de avaliocracia. Além disso, destaca seu caráter restritivo, na medida em que associa qualidade educacional ao resultado de avaliações de desempenho que não consideram a escola em sua totalidade analítica, bem como tem uma restrição à compreensão de formação humana, formação esta que se estende para muito além do que os testes padronizados podem alcançar.

Para além de colocar em questão a compreensão de que a qualidade acontece como resposta ao trabalho do professor, também questionamos o próprio conceito de qualidade baseado no desempenho dos estudantes.

Dar a ver que há outras condições necessárias para que a qualidade seja construída, implica em ter como perspectiva a construção de uma responsabilização participativa, em que poder público também tome para si suas responsabilidades. E haja, acima de tudo, processos de negociação entre todos os atores para a construção de uma qualidade negociada (BONDIOLI, 2004).

\section{Alguns depoimentos das egressas}

O questionário também contava com uma questão aberta para depoimentos diversos. Avaliamos como importante trazer uma reflexão sobre este conjunto de depoimentos. Não com a intenção de quantificá-los, pois a diversidade temática é grande, e cada um apresenta um sentido único e singular das experiências produzidas no momento da realização do curso de Pedagogia. O objetivo aqui é levantar elementos que aparecem nas respostas e que mostram a dimensão da compreensão do curso em suas experiências profissionais. Estas experiências são singulares e sociais. Elas demonstram marcas dos outros sujeitos e espaços com os quais o depoente manteve relação. Desde a referência ao ambiente universitário e sua contribuição formativa, passando pelas marcas deixadas pelos professores. As experiências também são dimensionadas no tempo posterior ao vivido, quando já acumularam tempos de atuação em distintos campos. Além disso, há 
ainda uma dimensão do quanto ele pode ser lido em sua diversidade nas propostas dos professores, que deixam marcas em diferentes egressas.

O curso de pedagogia da Unicamp não me preparou para a prática, mas me preparou para pensar a prática e isso fez com que eu pudesse buscar estratégias no trabalho. Duvido que um curso, qualquer curso, consiga ensinar alguém a entrar numa sala de aula e realmente dar aula, por isso acho importante que o curso ensine a pensar, e dar ferramentas para que nós possamos ter discernimento, criticidade, curiosidade para procurar metodologias quando nos depararmos com a realidade. (Depoimento 34)

Para mim, foi ótimo ter cursado Pedagogia na Unicamp. Me acrescentou muito em vários aspectos da vida. Muitas coisas poderiam ser melhores/diferentes? Sim, sempre (difíceis de colocar de maneira breve aqui). Mas acho difícil um lugar composto por seres humanos atingir a perfeição. Não pretendo seguir a carreira da docência, mas não tem relação com o curso e sim com a área e escolhas pessoais mesmo. (Depoimento 40)

Os anos iniciais do curso, com introdução às várias áreas: história, filosofia, sociologia foram ótimos. No entanto, falta criança, infância, educação infantil! Foram apenas 3 disciplinas sobre criança. Falta ARTE! Falta uma formação para uma Pedagogia de Corpo Inteiro! Falta pensar a Educação Especial desde o início! Falta um olhar filosófico para a Educação e menos conteudista! (Depoimento 54)

A base teórica oferecida pelo curso diferencia de muitos colegas formados por outras instituições. No meu caso, ingressei em 2000 e já comecei a atuar na rede pública em 2001, já tinha magistério, mas o curso oferece pouco conhecimento sobre a prática. (Depoimento 144)

Minha formação foi um divisor de águas em minha vida. Foi onde me encontrei: me formei para ser professora de escola pública e é o que sou hoje. Penso que tive uma excelente formação, que me instrumentalizou para ser uma profissional crítica, reflexiva e autônoma. E a formação não se limitou ao âmbito profissional, estando relacionada profundamente ao que hoje sou enquanto ser humano. (Depoimento 26)

A graduação no geral foi satisfatória, minhas dificuldades surgiram quando adentrei a sala de aula. Meu Deus! Como me vi perdida. Era pior que barata tonta. Hoje olhando para trás penso que a graduação poderia ter focado também na vivência em sala de aula, no cotidiano do professor. Por mais que fiz todos os estágios obrigatórios da graduação ainda sim, na minha experiência, não foram suficientes. Espero ter contribuído um pouquinho. $=\mathrm{D}($ Depoimento 83$)$ 
Gostei muito do curso, principalmente da base teórica dos primeiros anos (sociologia, filosofia, história da educação, antropologia). Os estágios tinham linhas muito diferentes e as disciplinas de PPP foram fracas. Hoje cursando mestrado sinto falta de uma base sólida de metodologia de pesquisa. Enquanto professora, a universidade me formou para sempre aprimorar meus conhecimentos, estudar é fundamental e eterno na vida do professor. (Depoimento 134)

Estes depoimentos passam pela compreensão que tiveram, em seu processo formativo na universidade, uma ênfase na formação pela pesquisa, que implicou na atuação como professora e na ampliação de sua perspectiva crítica, reverberando até mesmo em questionamentos sobre o próprio curso. E também é atravessado por sugestões. Estas sugestões estão muito vinculadas às histórias vividas em seu âmbito profissional, desde a necessidade de ter mais estudos na educação especial, por conta da ampliação da inclusão de pessoas com deficiências no interior da educação regular, passando pela necessidade de estudos voltados para as questões de gênero e as relações étnico-raciais.

Todo o conjunto de falas indica o quão amplo e complexo é o espectro de atuação do profissional pedagogo, mesmo no interior da escola. E há subjetividades sendo produzidas, sendo constituídas nas diferentes relações estabelecidas.

Um projeto de formação como aqueles que estão em vigor, defendidos pelas Diretrizes definidas na resolução do CNE/CP 2/2019, bem como a Deliberação do CEE/SP 154/17, pressupõe que é possível fazer o apagamento dessas singularidades, trazendo à tona uma questão central que é o controle na perspectiva tecnicista de fazer educação, como vimos apontando.

\section{Palavras que não finalizam}

Trazer à tona a temática dos egressos do curso de Pedagogia no contexto das políticas de formação que vivemos é mostrar a complexidade do vivido. Este contexto se materializa em nível nacional pela política hegemônica, que tende a fazer o apagamento da participação dos movimentos que estudam, pesquisam e estão comprometidos com uma formação de professores mais ampla e que compreende o campo de atuação do professor da Educação Básica como complexo e construído nas relações sociais. Os dois documentos trazidos neste artigo representam este movimento hegemônico, tanto as Diretrizes presentes na resolução CNE/CP 2/2019 quanto a Deliberação 154/17 do CEE/SP. 
Reflexões sobre a política de formação inicial a partir de dados de egressas do curso de Pedagogia da UNICAMP

Estamos a falar, neste texto, das egressas do curso de Pedagogia da Unicamp, que tem sido frequentemente indicado como muito teórico, por diferentes gestores da educação paulista. Toda a história de sua construção, todo o movimento de discussões internas, as reformulações baseadas na defesa dos movimentos sociais do campo da formação de professores - todo esse conjunto de propostas e envolvimento com a formação docente é reduzido à crítica de que ele é teórico. Há uma história, aqui representada também pelo que as egressas dizem ou dão indícios do que lá viveram. $\mathrm{O}$ fato é que um discurso de que ele é fundamentalmente teórico passou a ser objeto central de crítica para respaldar uma perspectiva da defesa do discurso que o curso necessita de uma interferência externa, como é o caso do que enfatiza a reportagem da Folha de $S$. Paulo, citada em momento anterior do texto. Para nós, estão em jogo também a autonomia universitária e a tentativa de difundir uma imagem de ineficiência da universidade pública paulista como forma de questionar o investimento público que é feito na instituição.

Outra questão apontada aqui é o modo como o contexto destas reformulações está diretamente vinculado a um discurso que culpabiliza a formação de professores pelo desempenho educacional, sem, contudo, compreender as muitas tramas e a dinâmica que são vividas nas escolas, nos processos formativos, inclusive as tramas advindas dos contextos econômicos em que estamos inseridos. Contexto este que influencia, sobremaneira, as condições de aprendizagem da população em idade escolar.

A partir dos dados apresentados, na relação com as políticas educacionais atuais, apontamos preliminarmente alguns temas que mereceriam ser objeto de pesquisa por parte das instituições de ensino superior em iniciativas de estudo sobre trajetórias de egressos.

Os dados indicam que os professores formados na Unicamp - e temos a hipótese de que o mesmo ocorre com os professores formados nas outras universidades públicas paulistas - não são responsáveis pela qualidade da educação básica no estado de São Paulo, como quer fazer crer o CEE/SP, dentre outros órgãos legisladores sobre o campo da formação de professores. O número de profissionais egressos da universidade pública que se insere no quadro da educação escolar pública não é suficiente para corroborar a lógica discursiva da culpabilização individual para a qualidade ou não de nosso sistema educacional.

O discurso das professoras egressas da Unicamp mostra uma articulação importante e necessária de ser mais bem compreendida, que expõe a complexidade da atuação pós-formação inicial, as formas de ressignificar o campo, as realidades de 
trabalho tão distintas. As escolas, as redes de ensino não apresentam uma realidade homogênea. Como pensar um curso de Pedagogia que lida com realidades tão distintas?

E por último, mas não menos importante, os dados nos levam a refletir sobre as condições de inserção no mercado de trabalho, quando aponta um número de trabalhadores autônomos. O contexto que vivemos, de flexibilização das relações trabalhistas e da perda de direitos historicamente conquistados, estar a influenciar estas formas de ser trabalhador da educação.

\section{Referências}

AFONSO, Almerindo. J. Questões, objetos e perspectivas em avaliação. Revista Avaliação, Campinas; Sorocaba, SP, v. 19, n. 2, p. 487-507, jul. 2014

ANFOPE. Políticas de formação e valorização dos profissionais da Educação: conjuntura nacional avanços e retrocessos. Documento final do XVIII Encontro Nacional da Anfope. Goiânia: ANFOPE, 2016. Disponível em: http://www.anfope.org.br/documentos-finais/. Acesso em: 20 set. 2020. Acesso em: 20 novembro de 2020.

ANFOPE. Documento final do IX Encontro Nacional. São Paulo: ANFOPE, 1989. Disponível em http://www.anfope.org.br/wp-content/uploads/2018/05/9\%C2\%BAEncontro-Documento-Final-1998.pdf. Acesso em: 20 novembro de 2020.

BONDIOLI, Anna. O projeto pedagógico da creche e a sua avaliação: a qualidade negociada. Campinas: Autores Associados, 2004.

BRASIL. CNE. Resolução CNE/CP Nº 2, de 20 de dezembro de 2019.

DOURADO, Luiz F. Diretrizes curriculares nacionais para a formação inicial e continuada dos profissionais do magistério da educação básica: concepções e desafios. Educação \& Sociedade, Campinas, v. 36, n. 131, abr./jun. 2015.

DOURADO, Luiz F.; TUTTMAN, Malvina T. Formação do Magistério da Educação Básica nas universidades brasileiras: institucionalização e materialização da Resolução CNE/CP n. 2 de 2015. Formação em Movimento, v.1, n. 2, jul./dez. 2019. Disponível em: http://costalima.ufrrj.br/index.php/FORMOV/article/view/503/818 Acesso em: 20 novembro de 2020.

FREITAS, Helena Costa Lopes. Itinerário Educação no EM em SP. Formação de Professores - Blog da Helena. Disponível em: https://formacaoprofessor.com/2020/ 08/10/itinerario-educacao-no-em-em-sp-destruicao-da-formacao-superior-nos-cursosde-pedagogia. Acesso em: 20 novembro de 2020. 
Reflexões sobre a política de formação inicial a partir de dados de egressas do curso de Pedagogia da UNICAMP

FREITAS, Luiz Carlos. ANFOPE: Concepções predominantes nos anos iniciais e sua importância para luta atual. Revista Formação em Movimento, v.1, n.1, p.16-31, jan./jun. 2019. Disponível em: http://costalima.ufrrj.br/index.php/FORMOV/article/view/445/780 Acesso em: 20 novembro de 2020.

GONÇALVES, Suzane; MOTA, Maria Renata; ANADON, Simone. A Resolução CNE/CP n. 2 de 2019 e os retrocessos na formação de professores. Revista Formação em Movimento, Rio de Janeiro, v. 2, n. 4, jul./dez. 2020. Disponível em: http://costalima.ufrrj.br/index.php/FORMOV/article/view/610/896 Acesso em: 20 novembro de 2020.

JEFFREY, Débora; ASSIS, Ana Elisa Spaolonzi; GRANDIN, Luciane. O curso de licenciatura em pedagogia: uma análise das adequações normativas e curriculares. Revista Internacional Educação Superior, Campinas (SP), v. 2, n. 2, maio/ago. 2016.

LIBANEO, José Carlos. Pedagogia e pedagogos: inquietações e buscas. Educação em Revista, Curitiba, n. 17, p. 153-176, jun. 2001.

MORAES, Reginaldo. O golpe de 2016: suas raízes e perspectivas da resistência. In: KRAWCZYK, Nora; LOMBARDI, José Claudinei. O Golpe de 2016 e a Educação no Brasil. Uberlândia (MG): Navegando, 2018.

PAUL, Jean-Jacques. Acompanhamento de egressos do ensino superior: experiência brasileira e internacional. Caderno CRH, Salvador, v. 28, n. 74, maio/ago. 2015.

SORDI, Mara. R. L.; FREITAS, Luiz Carlos. Responsabilização Participativa. Retratos da Escola, Brasília, v. 7, n. 12 (2013)

SOUZA, Ângelo. O professor da educação básica no Brasil: identidade e trabalho. Educar em Revista, n. 48, abr./jun. 2013.

VARANI, Adriana; ZAN, Dirce; GRANDIN, Luciane. O curso de Pedagogia entre deliberações. Educação - UFSM, Santa Maria, v. 44, 2019.

ZAN, Dirce. A formação de professores em disputa: a experiência da Unicamp. Revista Formação em Movimento, Rio de Janeiro, v. 1, n. 2, jul./dez. 2019. Disponível em: http://costalima.ufrrj.br/index.php/FORMOV/article/view/524/823 Acesso em: 20 novembro de 2020.

Recebido em: 21 jan. 2021.

Aprovado em: 02 mai. 2021. 
* Adriana Varani é pedagoga, mestre e doutora em Educação. Professora da Faculdade de Educação da Unicamp (FE/UNICAMP), no Departamento de Ensino e Práticas Culturais e pesquisadora do Laboratório de Observação e Estudos Descritivos (LOED). Atualmente é vice coordenadora estadual da ANFOPE São Paulo.

E-mail: avarani@unicamp.br

ORCID: https://orcid.org/0000-0002-7480-4998

** Dirce Zan é pedagoga, mestre e doutora em educação pela Unicamp. É docente do Departamento de Ciências Sociais e Educação e pesquisadora do Grupo de Pesquisa em Políticas Públicas, Educação e Sociedade (GPPES) da FE/Unicamp. Suas pesquisas estão voltadas à temática da juventude e sua relação com a escola de ensino médio.

E-mail: dircezan@unicamp.br

ORCID: https://orcid.org/000-0002-3663-2232 